\title{
Expert elicitation survey predicts $37 \%$ to $49 \%$ declines in wind energy costs by 2050
}

\author{
Ryan Wiser ${ }^{1 \bowtie}$, Joseph Rand ${ }^{1}$, Joachim Seel', Philipp Beiter ${ }^{2}$, Erin Baker ${ }^{3}$, Eric Lantz ${ }^{2}$ and \\ Patrick Gilman"
}

\begin{abstract}
Wind energy has experienced accelerated cost reduction over the past five years-far greater than predicted in a 2015 expert elicitation. Here we report results from a new survey on wind costs, compare those with previous results and discuss the accuracy of the earlier predictions. We show that experts in 2020 expect future onshore and offshore wind costs to decline 37-49\% by 2050, resulting in costs $50 \%$ lower than predicted in 2015 . This is due to cost reductions witnessed over the past five years and expected continued advancements. If realized, these costs might allow wind to play a larger role in energy supply than previously anticipated. Considering both surveys, we also conclude that there is considerable uncertainty about future costs. Our results illustrate the importance of considering cost uncertainty, highlight the value and limits of using experts to reveal those uncertainties, and yield possible lessons for energy modellers and expert elicitation.
\end{abstract}

W ind power deployment has expanded rapidly and wind energy is now among the lowest-cost means of electricity supply and energy-sector decarbonization in many regions ${ }^{1-5}$. Underpinning these developments have been technology innovation and industry maturation (for example, turbine size, industrialization, risk mitigation, supplier competition), competitive incentives (for example, from introducing auctions to procure wind energy) and other factors (for example, steel prices, debt interest rates). Initially these cost reductions materialized in onshore wind ${ }^{6,7}$, but industry maturation and cost declines have accelerated for offshore wind over the past five years ${ }^{8}$.

Though recent years have seen extraordinary cost reductions, further scientific, engineering, manufacturing and commercial innovations are possible ${ }^{9,10}$. Now is an opportune time to reflect on the cost reductions already achieved and to assess additional cost-reduction opportunities that will influence wind's future role in global electricity supply and energy-sector decarbonization ${ }^{11-14}$.

Here we report on an elicitation of 140 global wind experts, seeking insight into the magnitude, uncertainty and drivers associated with future cost reductions. Expert elicitation leverages the knowledge of subject-matter experts to develop estimates of unknown or uncertain quantities ${ }^{15}$. It is especially useful when historical data are limited or when future conditions may differ from the past. Perhaps most importantly, elicitations enable future uncertainty to be assessed ${ }^{16}$. The cost of wind is highly variable across projects and time; uncertain technological and commercial developments will influence future costs. Methods that accept and estimate these variations and uncertainties are advantageous. An extensive literature provides guidance on conducting elicitations $s^{17-21}$. Expert elicitation has been used numerous times to forecast cost trajectories for energy technologies ${ }^{22}$.

Several other methods can also be used to forecast costs, each with advantages and disadvantages. Learning curves have been applied extensively to explain past wind cost trends, but when used to predict costs, they assume that future trends will follow the past $^{23-25}$. Engineering assessments involve design and cost modelling, but they often cover only a subset of possible advancements and are limited by the need to make many uncertain assumption $\mathrm{s}^{26}$.
Pricing from auctions and power purchase agreements for renewable energy have recently emerged as another means of estimating future costs, but generally only five years forward ${ }^{8}$. None of these methods typically provides deep insight into the probability of different cost estimates, though each comes with certain advantages-for learning curves and auctions, a clear empirical mooring to real data, and for engineering assessments, detailed technological richness. Ultimately, given the complexity of cost forecasting, each approach has its place. And, because the wind sector continues to evolve, continuous updating of assessments is warranted.

In 2015, we conducted a similar global expert elicitation predicting that substantial wind energy cost reductions were likely, despite a great deal of uncertainty ${ }^{27}$. As we show here, actual costs have declined even more rapidly than anticipated by experts in 2015. A new elicitation is important for multiple reasons. First, given substantial changes seen in the wind industry over the past five years, an updated assessment is needed-old forecasts are obsolete. Second, by conducting a similar elicitation five years later and assessing intervening trends, we can evaluate the earlier predictions. We discuss factors that may have contributed to the experts' underestimation of cost reductions, and we highlight the value and limitations of using experts to reveal uncertainties in future costs. The results yield tentative implications for the design and execution of expert elicitations as well as insights on the importance of cost uncertainty for energy-sector modellers and planners. Third, we maintain that expert elicitation remains a valid tool, despite the underestimation resulting from our previous work. As we describe, engineering assessments and learning curves from the 2015 time frame predicted costs no better than the 2015 elicitation. And, as described above, expert elicitation holds some advantages compared with other cost-forecasting methods. Finally, though similar in many respects, we leveraged lessons learned from the 2015 effort to make several changes to the 2020 survey.

\section{Wind power expert elicitation}

Elicitations can provide valuable insights, supplementing other forecasting approaches. However, they must address the various 

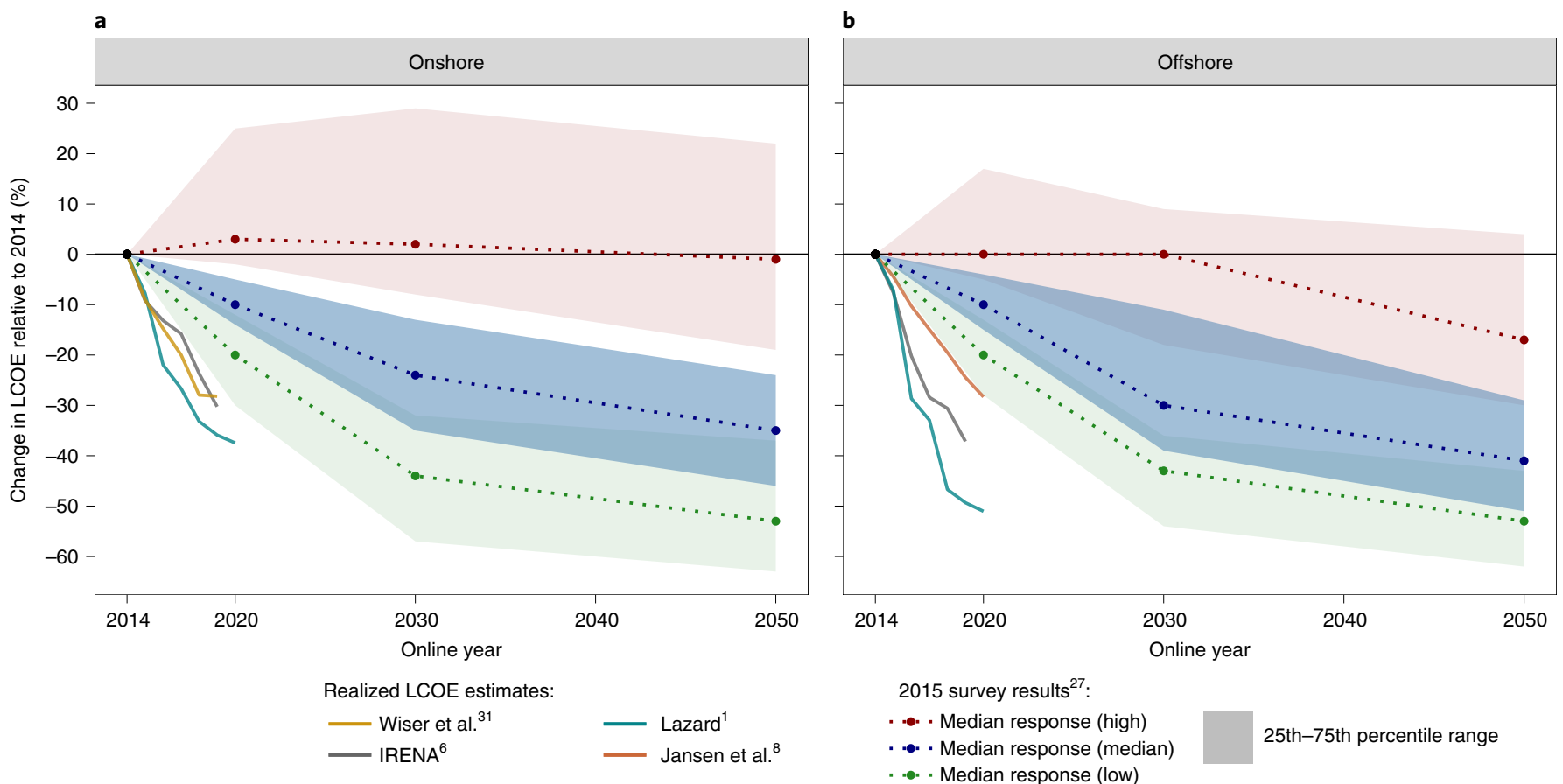

Fig. 1 | Results from the 2015 expert elicitation compared with recent published estimates of realized LCOE. a,b, Dotted lines with shaded areas extending to 2050 reflect the 2015 survey response median and the 25th-75th percentile range for the high-, median- and low-cost scenarios for onshore (a) and offshore (b) wind ${ }^{27}$. These are compared with a number of recent published estimates of the actual (realized) LCOE for onshore and offshore wind from 2014 to 2019-2020 (solid lines) ${ }^{1,6,8,31}$. The 2020 survey results are not plotted in this figure.

motivational or cognitive biases that influence expert responses. Advocacy or desirability bias may make wind experts unduly optimistic about wind's future ${ }^{28}$. Anchoring and availability heuristics may be at work. And experts may tend to rely on a common set of knowledge sources (studies or people), resulting in a degree of groupthink. Research has also shown that experts sometimes underestimate the possibility of technological change or are overconfident in their assessments, yielding inappropriately narrow uncertainty bound ${ }^{22}$. The challenges of validating elicitation accuracy and identifying sources of inaccuracies make the gravity of these biases unclear $^{29}$. Our wind elicitations-conducted five years apart-offer insight in this regard.

The elicitation discussed here is broadly consistent with our earlier effort in terms of scope, sample, questions and functionality, enabling an update of the 2015 assessment and a comparison of the two sets of elicitation results. The online, self-administered survey covers three wind applications: onshore, fixed-bottom offshore and floating offshore. Our analysis again centres on potential changes in levelized cost of energy (LCOE), in real 2019 US dollars (US\$) per megawatt-hour (MWh). LCOE is used to assess the cost of power generation assets with varying capital-recovery periods and cash-flow profiles. LCOE is less useful when comparing different electric-generation types ${ }^{30}$, but it is appropriate for assessing the unit costs of individual resources and tracking those costs over time. Minimizing LCOE is a primary goal of the wind sector. We asked respondents to estimate the LCOE of a typical (median) project in a baseline year of 2019. We then asked them to estimate LCOE for typical projects in 2025, 2035 and 2050 under three scenarios: low (only a $10 \%$ chance that typical LCOE will be lower), high (only $10 \%$ chance that typical LCOE will be higher) and median (equally likely that LCOE will be higher or lower) cost futures. We asked the experts to consider only factors that affect the entire industry, such as technology advancement or general changes in site conditions. We asked them to ignore exogenous macroeconomic factors, such as materials prices and risk-free interest rates, as well as any short-term effects of coronavirus disease 2019 (COVID-19). For the 2019 baseline and the three 2035 estimates, we requested details on five core LCOE inputs: (1) capital costs (CapEx, US\$ $\mathrm{kW}^{-1}$ ), (2) operating expenditures (OpEx, US\$ $\mathrm{kW}-\mathrm{yr}^{-1}$ ), (3) energy output (capacity factor, \%), (4) project life (yr) and (5) financing costs (after-tax, nominal weighted-average cost of capital, WACC (\%)). We asked for LCOE estimates for 2025 and 2050, but without detail on the five LCOE inputs. We did not ask for a baseline 2019 LCOE estimate for floating offshore wind, given the nascent state of commercial deployment.

As described in Methods, we leveraged lessons learned from the 2015 effort to improve the 2020 survey. For example, we required respondents to provide a 2019 baseline LCOE estimate from which their future expectations could be compared. In contrast, the 2015 survey offered respondents a predefined 'default' 2014 baseline value and gave them the option (but not the obligation) to update that value, potentially creating anchoring bias. We also asked each respondent for information on project and site conditions for their 2019 baseline and 2035 median-LCOE estimates. The responses to these questions enable a deeper understanding of LCOE expectations, and specifically the degree to which they are impacted by systematic technology change or changes in project sites and characteristics. We had no analogous questions in the 2015 survey.

Additional details on these and other aspects of our approach are provided in Methods and in the Supplementary Methods appended to our earlier paper $^{27}$. Ultimately, 140 experts responded to our online survey. We received 97 responses for onshore wind, 71 for fixed-bottom offshore wind and 37 for floating offshore wind. As highlighted in Methods, most respondents hail from Europe and North America; respondents come from a wide range of organizational types. Participants were told that their names and affiliations would be listed in the final paper, but that their individual survey responses would not be attributed to them or their organizations. 


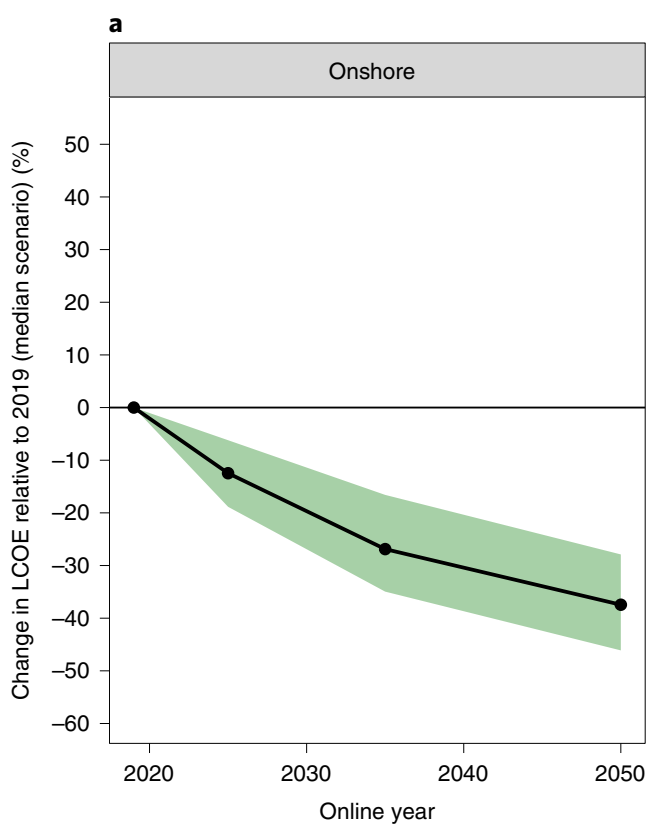

b
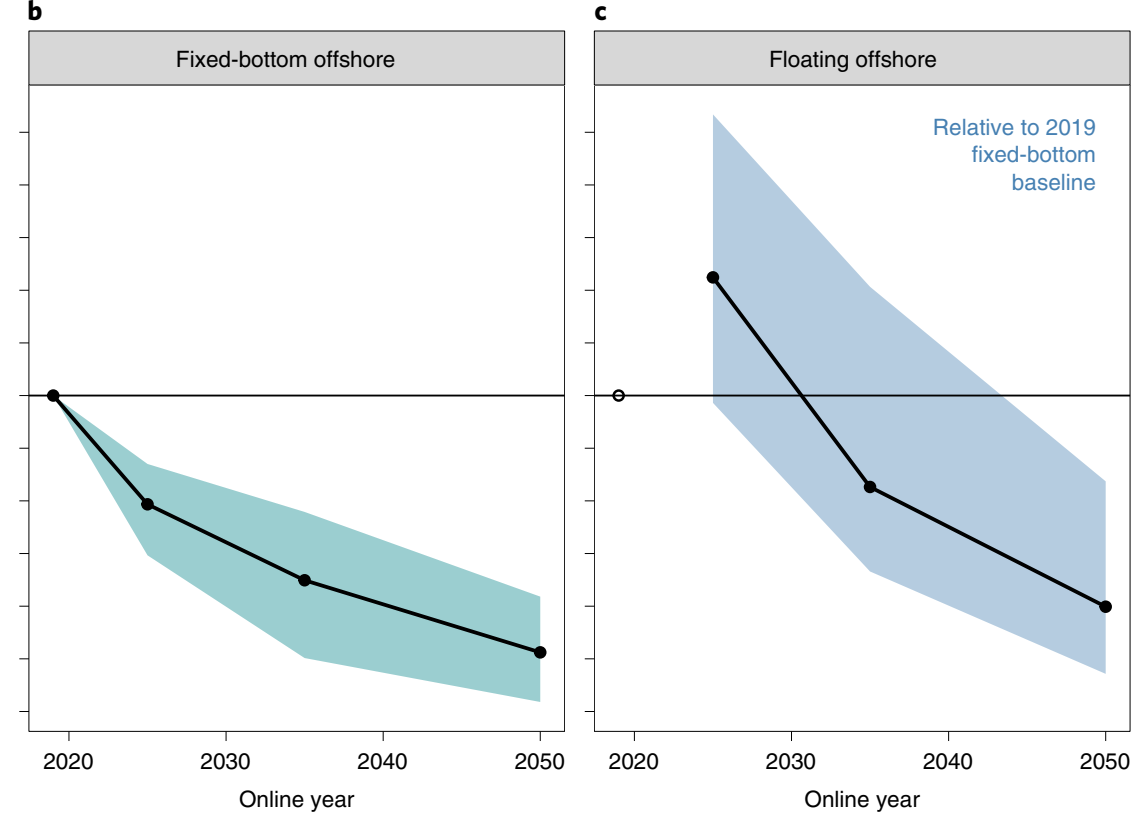

$\rightarrow$ Median respondent

25th-75th percentile range

Fig. 2 | Expected LCOE changes in the median scenario in percentage terms relative to 2019 baseline values. a-c, From the 2020 elicitation, the medians of expert responses in terms of percentage LCOE reductions are shown by the lines/markers, and the shaded areas represent the 25th-75th percentile ranges of all responses for the median scenario. Panels show results for onshore (a), fixed-bottom offshore (b) and floating offshore (c) wind. Floating offshore wind changes are compared with expert-specific 2019 baselines for fixed-bottom offshore wind, depicted in the figure as the empty circle; given the nascent state of floating offshore wind, experts predict that LCOE in 2025 will be higher than 2019 fixed-bottom costs.

\section{Assessing the 2015 elicitation in light of recent trends}

Before turning to the 2020 survey results, we first reflect on the 2015 survey results and industry developments since 2015. For onshore wind, a variety of recent publications report that actual (or realized) average LCOE declined by $28-36 \%$ from 2014 to 2019, globally ${ }^{1,6}$ and in the United States ${ }^{31}$. This is far greater than the median expert from the 2015 elicitation anticipated, even in the low-cost $(10 \%$ probability) scenario (Fig. 1). Offshore wind LCOE fell $28-49 \%$ from 2014 to 2019 on the basis of a variety of recent global ${ }^{1,6}$ and European Union ${ }^{8}$ estimates, also far greater than predicted in 2015.

The reasons for these missed predictions are challenging to parse and, after only five years, it is perhaps inappropriate to judge the experts' long-term predictions. Finance and materials prices played a role: the cost of capital dropped to historically low levels ${ }^{32,33}$, and relevant commodity (for example, steel) prices declined. These factors were driven in part by macroeconomic changes that we asked respondents not to consider. Supplementary Note 1 shows that accounting for these factors only helps to modestly narrow the gap between expected and realized LCOE (by perhaps 5\% of LCOE for onshore wind).

The steep cost reductions also coincided with increased use of competitive procurement (for example, auctions) for wind, replacing, in many cases, fixed payment schemes. Experts may have under-predicted cost pressures induced by auctions and other forms of competitive procurement ${ }^{8}$. Cost reductions, meanwhile, increased demand for offshore wind, leading to further industrialization of not only turbines but also foundations, installation and other balance-of-station elements. As experience was gained and project risks were better understood, cost contingencies narrowed. Additionally, technical advancements allowed turbines to grow more rapidly than experts predicted ${ }^{26,34,35}$. Increased turbine capacity can reduce CapEx and OpEx because fewer turbines must be installed and operated for a given amount of power production.
Growth in hub heights and rotor diameters can increase capacity factors. Respondents anticipated increased turbine size in 2015 and viewed it as the most critical driver for LCOE reduction ${ }^{27}$. The experts forecasted growth in typical turbine capacities from 2014 to 2030: for onshore, from 1.9 to 3.25 MW in North America and from 2.5 to $3.75 \mathrm{MW}$ in Europe, and from 3.4 to $11 \mathrm{MW}$ for European offshore. In 2019, actual capacities were 2.5 MW (US onshore ${ }^{31}$ ), 3.1 MW (Europe onshore ${ }^{36}$ ) and 7.0 MW (Europe offshore ${ }^{37}$ ), representing $44-48 \%$ of what was expected by 2030 over just 5 (31\%) of the 16 intervening years.

The experts from our 2015 elicitation were not alone in missing the rapid pace of recent advancement. For onshore wind, 2015 respondents were generally more aggressive in their predictions than the broader literature at the time; for offshore, they were more conservative. In both cases, however, 2015 responses fell within the range of other forecasts ${ }^{27}$. Median-scenario expert predictions for onshore wind were also consistent with historically observed LCOE-based learning rates. Realized 2014-2019 LCOE values depicted in Fig. 1, however, reflect a global learning rate in which LCOE declines by $35-46 \%$ for each doubling of cumulative capacity. This is two to four times greater than the long-term historical trend. Thus, predicting onshore wind costs on the basis of historical learning would have proven as equally inaccurate as the median 2015 survey results, at least to 2019, and would not have provided the full range of uncertainty and the underlying reasons for it. For offshore wind, a cost-reduction history was largely absent at the time of the earlier survey, with some studies showing notable LCOE increases from 2000 to $2014^{38}$. As such, any extrapolation of historical learning rates would probably have projected increasing LCOE. While the experts accurately anticipated a break from the historical trend, they missed the tremendous speed of industry maturation. The realized costs in Fig. 1 imply a global learning rate from 2014 


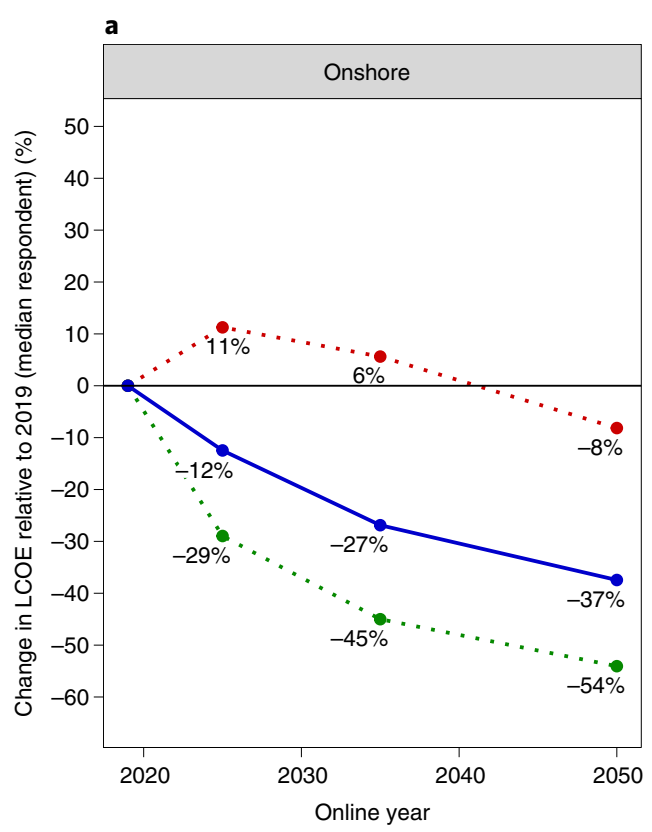

b

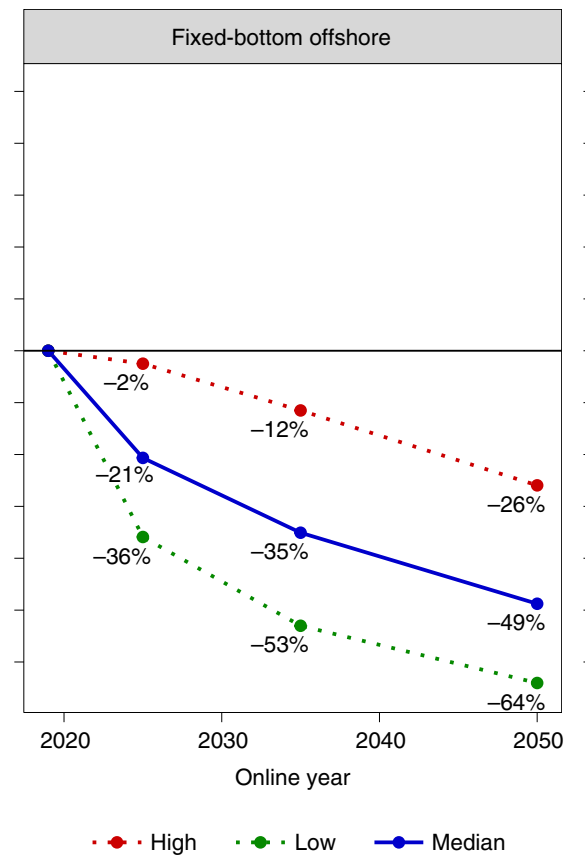

c

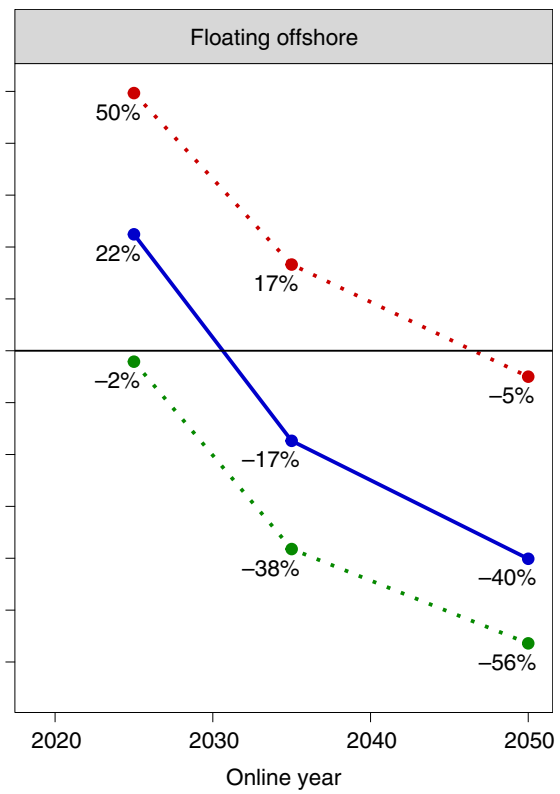

Fig. 3 | Estimated change in LCOE over time across all three scenarios from the $\mathbf{2 0 2 0}$ elicitation. a-c, Shown are the median of expert responses for expected LCOE reductions in the median scenario as well as the low scenario and high scenario in percentage terms relative to 2019 baseline values. Panels show results for onshore (a), fixed-bottom offshore (b) and floating offshore (c) wind. Floating offshore wind is compared against the 2019 baseline for fixed-bottom offshore.

to 2019 of $14-33 \%$ on the basis of growth in cumulative offshore wind capacity.

Some experts in 2015 predicted five years of future costs better than others. As shown in Supplementary Note 2, we employ two types of accuracy score and find statistical evidence that more prescient experts tended to be within the 'leading expert' cohort (offshore), had broad (system level, rather than component level) wind market and/or technology expertise (onshore), and self-identified as having knowledge about multiple regions (onshore). Organizational type has no statistical relationship with prediction accuracy. The more-accurate predictions came from experts who were systematically more optimistic in their low- and median-cost estimates and those who expressed greater uncertainty in their predictions through a larger spread between those two scenarios.

Overall, these findings illustrate the challenges of forecasting costs, regardless of method, and highlight the need to respect uncertainty in cost trajectories. Though the 2015 elicitation suggests experts may understate uncertainty, expert elicitation remains among the only cost-forecasting methods that can directly estimate the probability of different outcomes. There is no reason to believe that it is less accurate than other methods, as applied to wind energy.

\section{Current expectations for future costs}

We now summarize the 2020 elicitation results and compare the 2015 and 2020 results to assess how predictions changed over this 5 -year period. The 2020 elicitation demonstrates the possibility of substantial further cost declines and the uncertainties associated with those advancements.

Figure 2 highlights LCOE-reduction expectations from the 2020 elicitation, and is focused on the median scenario in which it is equally likely that LCOE will be higher or lower. Across all wind applications, LCOE is anticipated to decline by $17-35 \%$ in 2035 and $37-49 \%$ in 2050 (floating offshore wind costs are compared with fixed-bottom 2019 baselines).
The 25th-75th percentile ranges in the median scenario (Fig. 2) indicate the uncertainty surrounding cost reductions, which in this instance is driven by varying perspectives across experts. The extent of those uncertainties is further confirmed by the experts' LCOE predictions across all three scenarios, inclusive of the low cost (only a 10\% chance that typical LCOE will be lower) and high cost (only $10 \%$ chance that typical LCOE will be higher) cases (Fig. 3). The low-cost scenario reflects what might be possible with greatly enhanced research, development and deployment. Under that scenario and across all applications, experts in 2020 predict LCOE reductions of $38-53 \%$ by 2035 and $54-64 \%$ by 2050 . The high-cost scenario suggests that slower reductions or even cost increases are possible. The 2015 predictions discussed in the previous section show that even low-cost estimates can be overly conservative and suggest that the wide results range in Fig. 3 may understate the uncertainty surrounding future costs.

Figure 4 presents the median-scenario LCOE results in absolute (US\$ $\mathrm{MWh}^{-1}$ ) terms, not only from the 2020 elicitation but also from the earlier one from 2015. Experts in 2020 generally expect onshore wind to remain less expensive than offshore, and fixed-bottom offshore to remain less expensive than floating. However, they anticipate greater reductions in offshore LCOE than onshore LCOE in relative and absolute terms. The 2020 experts also expect the gap between fixed-bottom and floating offshore costs to narrow. Consistent with the latter finding, 2020 experts expect the water depth at which floating becomes less costly than fixed-bottom offshore wind to decline over time from $>80 \mathrm{~m}$ in 2019 to $>60 \mathrm{~m}$ in 2035 . By 2035, the median expert predicts that $11-25 \%$ of all new offshore projects globally will feature floating foundations.

The LCOE differences between the two surveys are profound. Experts in both surveys anticipated median-scenario LCOE reductions of roughly similar magnitudes in percentage terms, in effect expecting similar relative levels of cost reduction; the same is true for the low- and high-cost scenarios. However, the starting (2014 or 2019) baseline values differ dramatically, reflecting the steep 


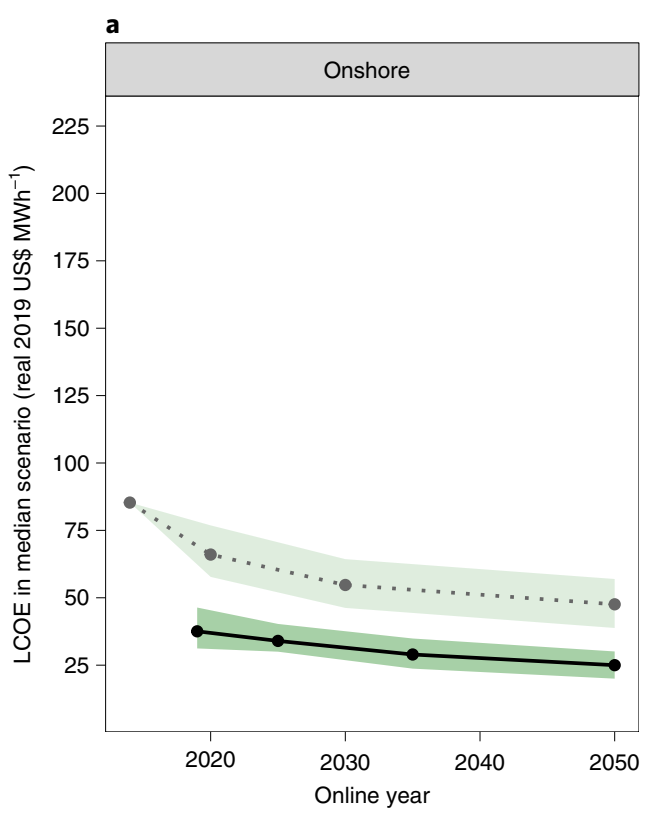

b

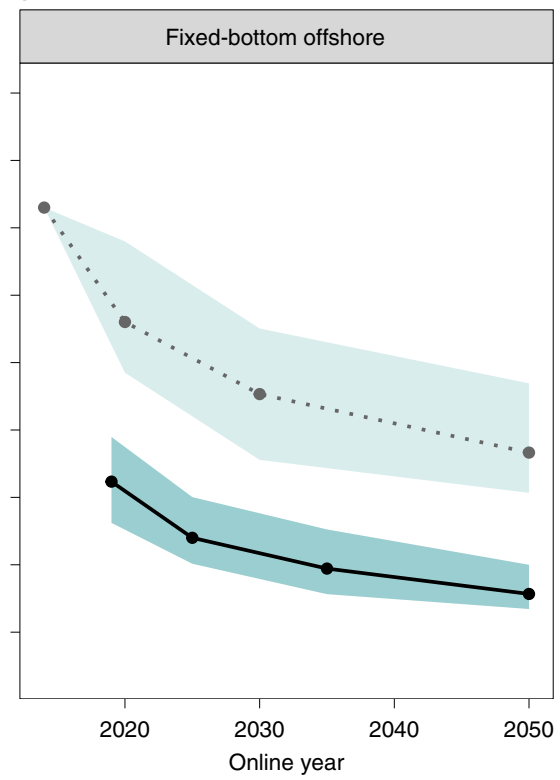

$\rightarrow$ Median respondent (2020) - Median respondent $(2015)^{27}$

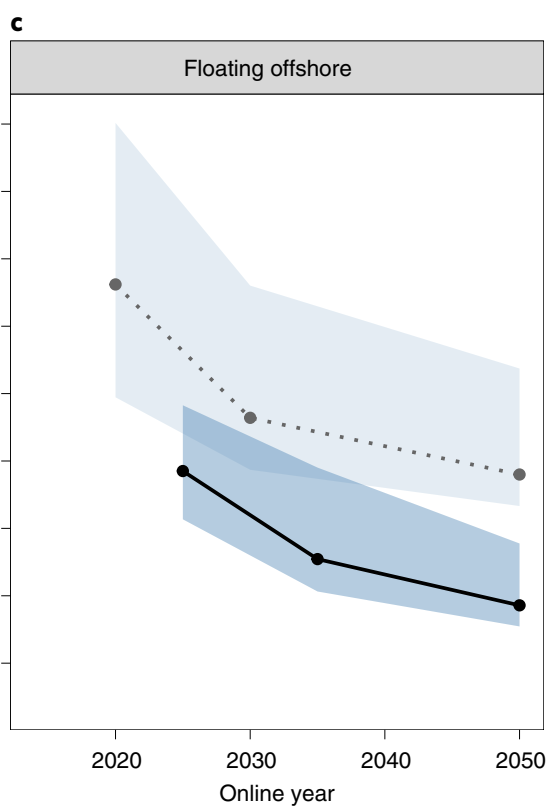

25th-75th percentile range

Fig. 4 | Estimates of median-scenario LCOE in the 2020 and 2015 surveys. a-c, Lines/markers indicate the median expert response for the median-LCOE scenario, and the shaded areas represent the 25th-75th percentile ranges of all responses for that median scenario. Shown are results from the 2020 survey, as well as the earlier 2015 survey $^{27}$. Panels show results for onshore (a), fixed-bottom offshore (b) and floating offshore (c) wind. Supplementary Fig. 1 provides similar data across all three LCOE scenarios, focused solely on the 2020 survey.

decline in actual LCOE during the intervening years. Experts in 2020 anticipate median-scenario 2050 LCOE that is $43 \%$ (onshore), $54 \%$ (fixed-bottom offshore) and 45\% (floating offshore) lower than what was expected in 2015.

Different LCOE expectations among experts partly reflect regional considerations. In 2020, experts anticipate that North America will host lower-cost onshore projects than other regions, with Europe hosting lower-cost offshore projects (Fig. 5). Segmenting experts into other cohorts generally reveals only modest differences in LCOE expectations (Supplementary Note 3). As highlighted earlier, evidence suggests that the leading experts in 2015 predicted more accurately; in 2020, however, the smaller group of pre-identified leading experts had only slightly more aggressive cost-reduction expectations that are not statistically different from the full sample. As in $2015^{27}$, differences based on organizational and expertise type are modest and generally not statistically significant.

\section{Factors influencing LCOE reductions}

On the basis of the 2020 survey results, turbine and site characteristics both influence wind LCOE, and the expected median-case LCOE reductions come despite a predicted trend towards less-attractive wind sites. For onshore wind, experts expect median annual average wind speed (at $100 \mathrm{~m}$ above ground) for new projects to decline from $7.9 \mathrm{~m} \mathrm{~s}^{-1}$ in 2019 to $7.5 \mathrm{~m} \mathrm{~s}^{-1}$ in 2035 , presumably a result of a general tendency to build projects in higher-wind-speed areas first. For fixed-bottom offshore wind, experts forecast the median project in 2035 to be located farther from shore $(70 \mathrm{~km}$ (2035) versus $40 \mathrm{~km}$ (2019)) and in deeper water (42 m (2035) versus $30 \mathrm{~m} \mathrm{(2019)).}$ Offsetting these trends, experts predict the fixed-bottom median project to be substantially larger: 900-1,299 MW (2035) versus $500-699 \mathrm{MW}$ (2019). The annual average wind speed, at $9.5 \mathrm{~m} \mathrm{~s}^{-1}$ at $100 \mathrm{~m}$ above water, is not expected to change over this period. This suggests that as projects move farther from shore, experts believe that wind site quality can be maintained (and, with turbine size increasing, hub-height level wind speed would increase). Relative to fixed-bottom in 2035, experts forecast the median floating offshore project to be smaller $(500-699 \mathrm{MW})$, farther from shore $(100 \mathrm{~km})$ and in deeper water (100-199 m), and to experience higher annual average wind speeds $\left(10 \mathrm{~m} \mathrm{~s}^{-1}\right.$ at $100 \mathrm{~m}$ above water).

Growth in turbine size may be an important driver of lower LCOE, offsetting the potential movement towards less-attractive wind sites. In 2020, experts have become even more optimistic about further growth in turbine capacity ratings, hub heights and rotor diameters (Fig. 6). In 2015, the median expert predicted that a typical onshore turbine installed in 2030 would have a rated capacity of 3.25 MW. In 2020, the forecast is for a 5.5 MW rating in 2035. For offshore wind, 2015 respondents predicted an $11 \mathrm{MW}$ average for 2030, whereas the 2020 respondents indicate 17 MW by 2035 .

In part reflecting these expectations about site and turbine characteristics, Fig. 7 summarizes expert views on how median-scenario LCOE reductions between 2019 and 2035 might be achieved. For onshore wind, CapEx and capacity factor improvements are most important. For fixed-bottom offshore wind, increased capacity factors are less important, but CapEx and other factors more so. Summarizing results for floating offshore wind is complicated, because we compare expert perspectives for 2035 to 2019 fixed-bottom baselines. However, given the higher wind speeds anticipated for floating projects than for fixed-bottom projects, it is not surprising that capacity factors dominate 2035 floating offshore wind LCOE estimates when compared with 2019 fixed-bottom baselines. The floating CapEx in 2035 is expected to be higher than the 2019 CapEx for fixed-bottom. For additional details on respondent-level perspectives on absolute LCOE, CapEx, OpEx, capacity factor, design life and WACC across all three scenarios, see Supplementary Figs. 3-8. For differences across regions and respondent cohorts, see Supplementary Tables 1-3.

\section{Comparison with past trends and other forecasts}

Comparing elicitation-based forecasts with historical learning rates can indicate the degree to which experts expect costs to continue 

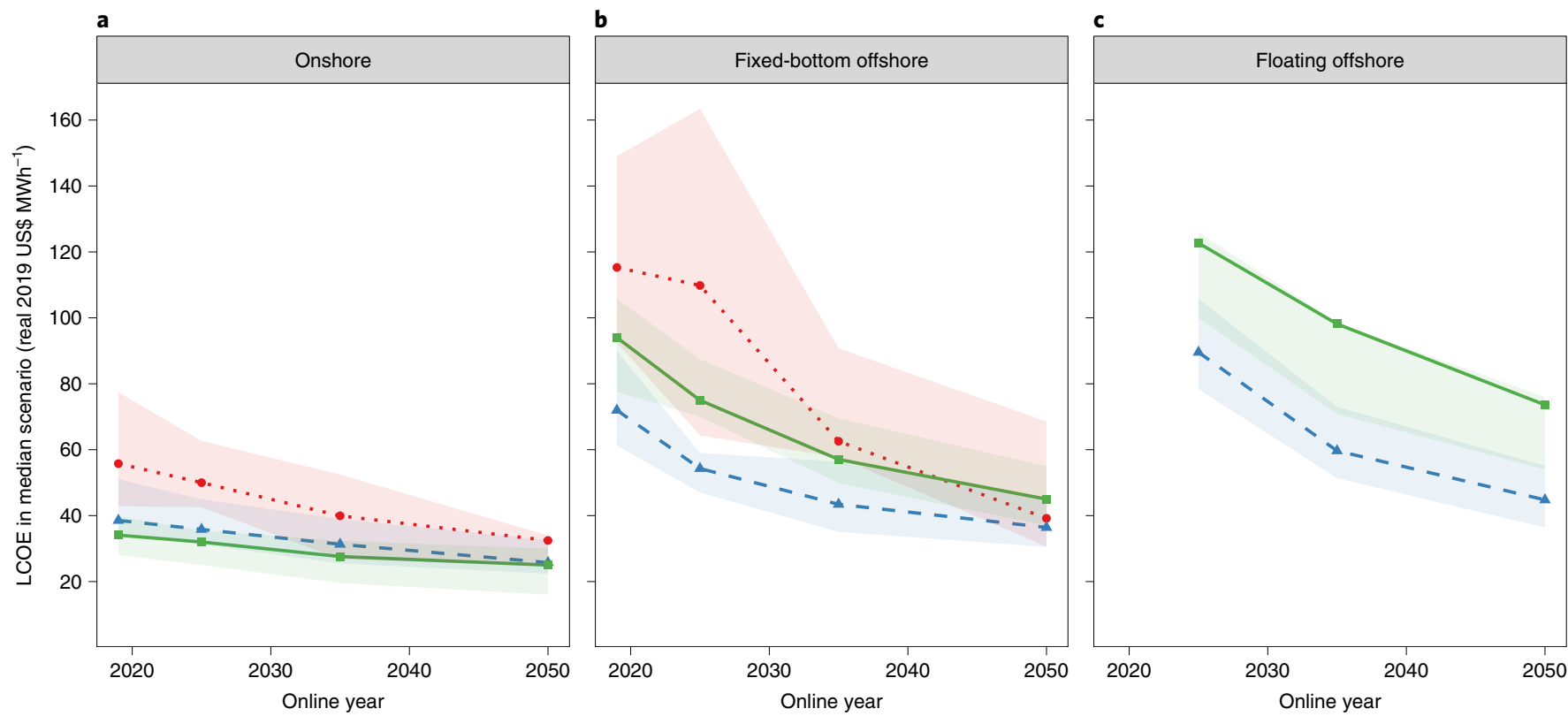

... Asia -A- Europe $=$ North America

25th-75th percentile range

Fig. $\mathbf{5}$ | Estimates of median-scenario LCOE from the $\mathbf{2 0 2 0}$ survey by region of the world. a-c, Lines/markers indicate the median expert response for the median-LCOE scenario, and the shaded areas represent the 25th-75th percentile ranges of all responses for that median scenario. Panels show results for onshore (a), fixed-bottom offshore (b) and floating offshore (c) wind. Only regions with five or more respondents are presented, but sample size remains small in some cases: onshore (Asia, 6; Europe, 39; North America, 46), fixed-bottom offshore (Asia, 5; Europe, 52; North America, 18) and floating offshore (Europe, 29; North America, 5).

a

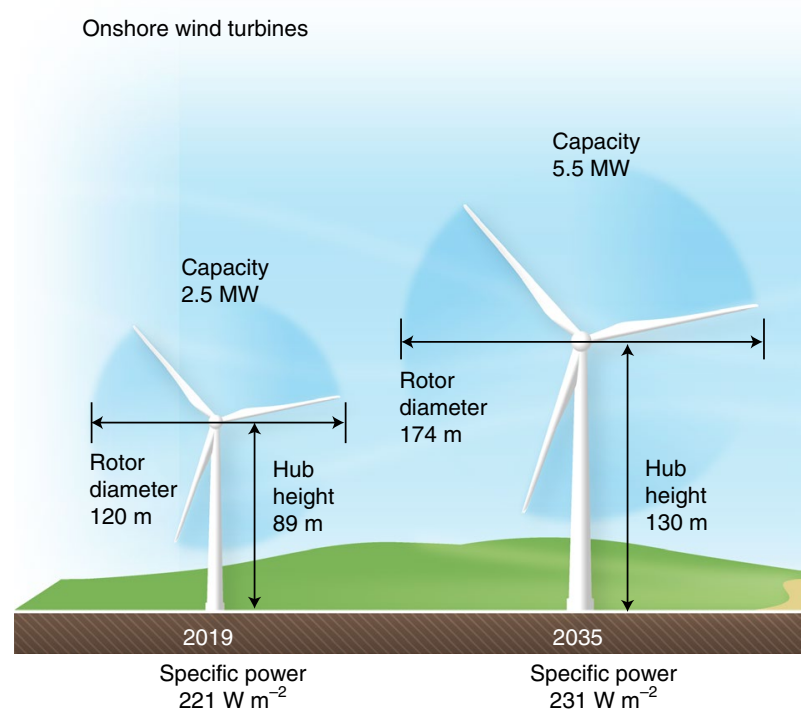

b

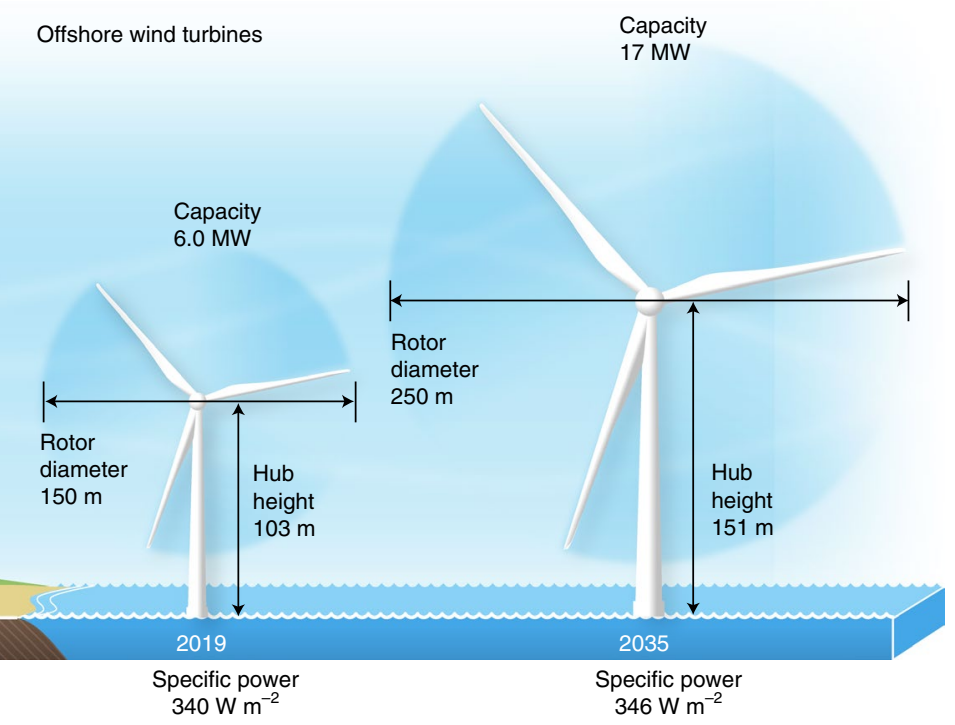

Fig. 6 | Expected turbine size in 2035 for onshore and offshore wind, compared with 2019 medians. a,b, The survey asked respondents to estimate the median turbine size for newly built projects in 2035. Results for the median respondent are presented here, contrasted with median-turbine sizes for projects installed in 2019. For offshore wind, a global 2019 median is depicted ${ }^{37}$. For onshore wind, a US median is depicted given lack of data to estimate a global median ${ }^{31}$. Panels show results for onshore (a) and offshore (b) wind. For offshore, respondents were asked to predict turbine size considering both fixed-bottom and floating applications.

on historical paths. Evaluating how elicitation results compare with other contemporaneous forecasts can suggest whether methodological differences account for variations in expected cost trajectories.
For onshore wind LCOE, long-term historical learning rate estimates are $10-20 \%$ (refs. $^{27,39,40}$ ), meaning that every doubling of global cumulative wind capacity yields an average reduction in 


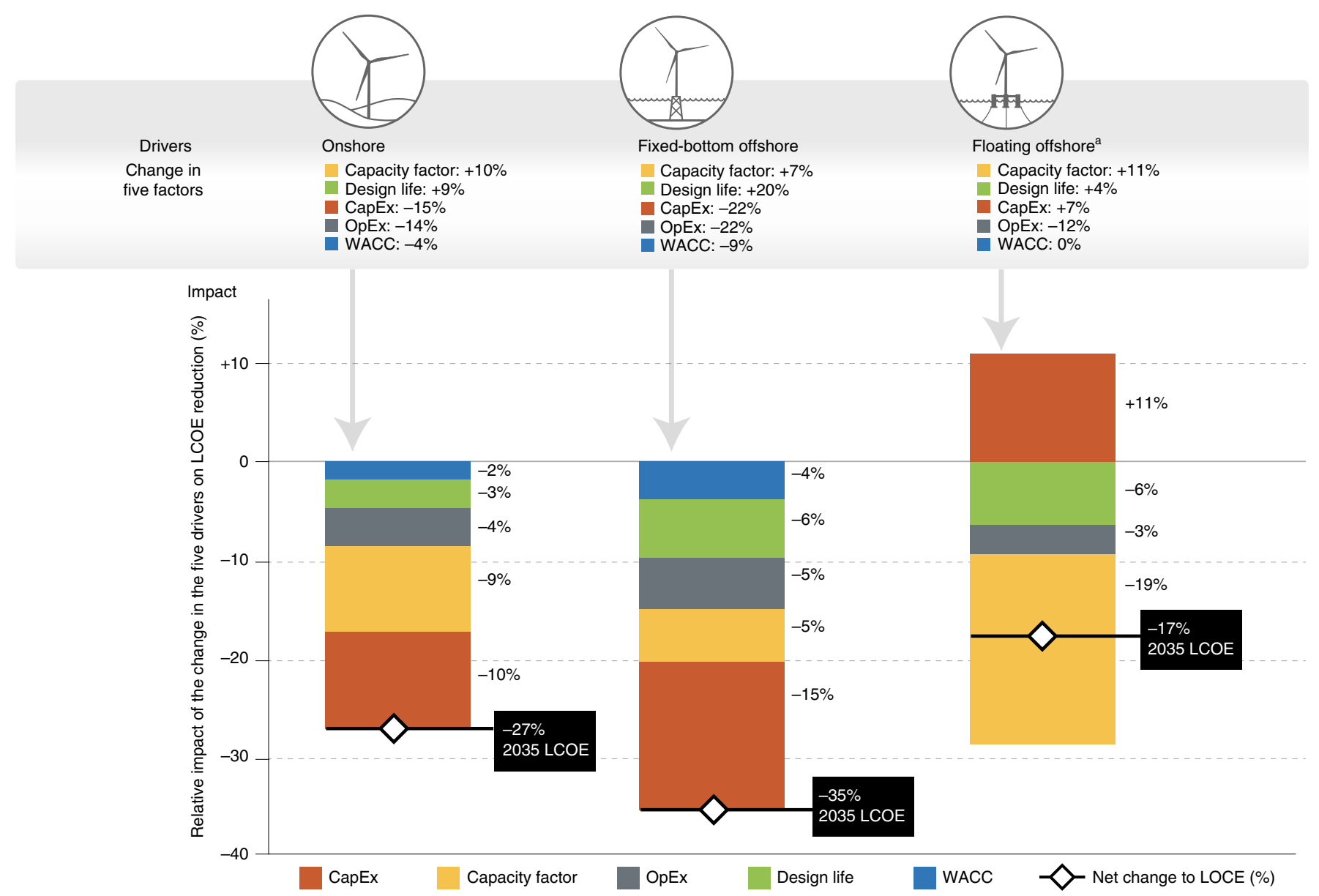

Fig. 7 | Impact of five drivers for median-scenario LCOE reduction in 2035. For each wind application, the figure presents the median respondent's 2019 to 2035 percentage change in each of the five drivers that influence LCOE (top). We then use the respondent-level data to estimate the relative impact of these various changes on the LCOE reduction between 2019 and 2035 (bottom). Panels show results for onshore (left), fixed-bottom offshore (centre)

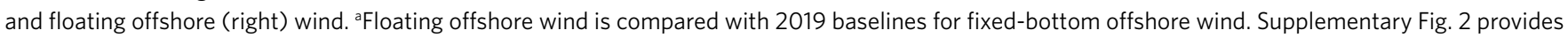
similar analysis for the low-LCOE scenario.

LCOE of 10-20\%. Combining the median-scenario expected LCOE reduction from 2019 to 2035 with a range of deployment projections for cumulative global onshore (or total) wind capacity ${ }^{41-45}$ yields a median implicit LCOE learning rate of 13\% (10-19\% across all deployment projections). This rate is consistent with historical long-term learning but lower than the $35-46 \%$ calculated for 2014 to 2019 .

Figure 8 contrasts the 2020 survey results with a range of other contemporaneous forecasts. The experts are more optimistic about future onshore wind costs than several other forecasts due to lower assumed LCOE baseline values (International Renewable Energy Agency (IRENA) ${ }^{45}$ and DNV GL ${ }^{44}$ ), stronger percentage cost reductions (US Energy Information Administration (EIA) ${ }^{46}$ ) or both (International Energy Agency (IEA) ${ }^{41}$ ). Though not depicted in the figure, the experts are also more optimistic than assumptions in most integrated assessment models, at least as summarized in $2017^{3}$. Forecasts from BloombergNEF ${ }^{47}$ and the National Renewable Energy Laboratory (NREL) ${ }^{48}$ fall somewhat below the full survey results, though are more closely aligned with the respondents' perspectives on LCOE in North America (Fig. 5).

Offshore wind comparisons are more complicated because LCOE increased from 2000 to $2014^{38}$, followed by steep reductions ${ }^{8}$. Combining the median-scenario LCOE reduction from 2019 to 2035 for fixed-bottom offshore wind with a range of deployment projections for cumulative global offshore wind capacity ${ }^{43-45}$ yields a median implicit LCOE learning rate of $14 \%$. This forward-looking learning rate is at the bottom of the $14-33 \%$ range estimated for the 2014-2019 period.

Expert assessments for offshore wind percentage cost reduction relative to a recent-year baseline are generally in line with BloombergNEF ${ }^{47}$, but are more conservative than other recent forecasts including from IEA ${ }^{41}$, IRENA ${ }^{45}$, DNV GL ${ }^{44}, \mathrm{NREL}^{48}$ and Wood Mackenzie $^{49}$. However, as depicted in Fig. 8, these differences are largely due to different baseline values: absolute LCOE estimates in 2030 and beyond are highly consistent across all of these sources, except EIA ${ }^{46}$, which projects considerably higher costs. As with onshore wind, assumptions used in integrated assessment models ${ }^{3}$ appear conservative relative to expert assessments.

With notable exceptions ${ }^{48}$, uncertainty in future costs is not considered in most of the other forecasts cited above. They instead offer point estimates for future LCOE. Elicitation results provide a rich source of additional information by estimating these uncertainties.

\section{Conclusions}

Wind energy cost reductions have accelerated over the past five years-much more than predicted by most experts, learning-curve extrapolation or engineering assessments. Experts anticipate substantial future reductions. Consistent with our previous expert 


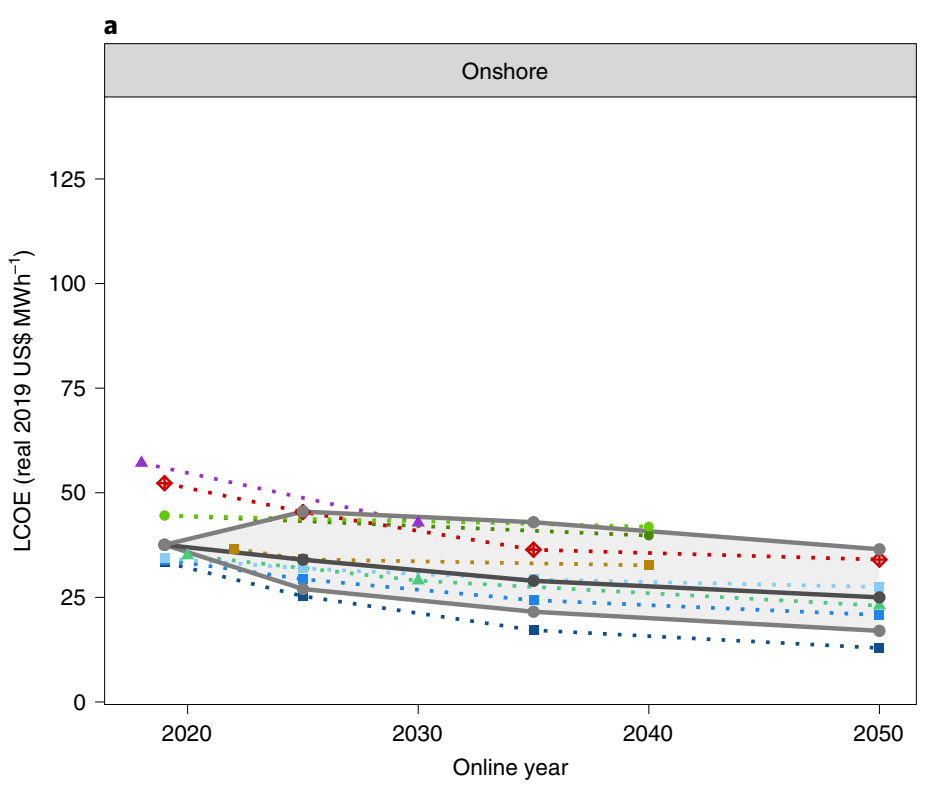

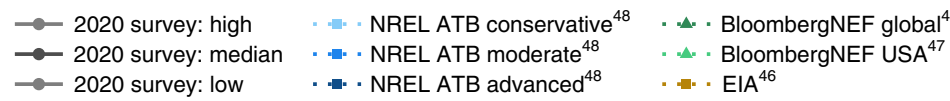

b

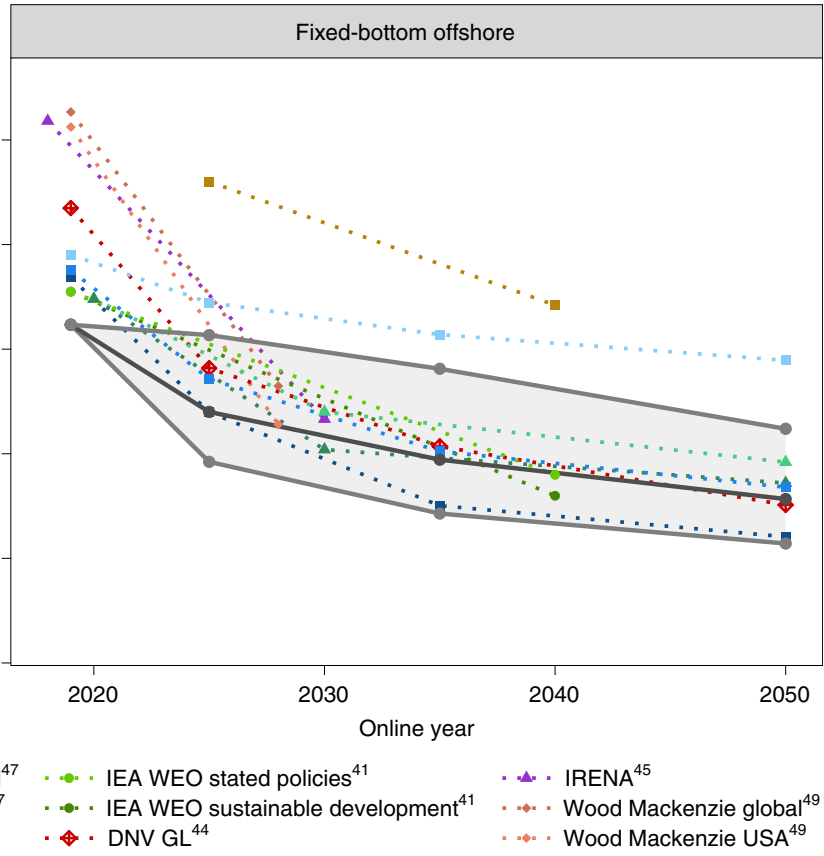

Fig. $\mathbf{8}$ | Comparison of $\mathbf{2 0 2 0}$ survey results with other contemporaneous LCOE forecasts. $\mathbf{a}, \mathbf{b}$, Depicts the median of expert responses for LCOE in the median, low and high scenarios for onshore (a) and offshore (b) wind. The shaded areas span the 2020 survey results. Survey results are compared with a range of other LCOE forecasts ${ }^{41,44-49}$. Note that such comparisons are imperfect; for example, some forecasts include offshore transmission-infrastructure costs in LCOE whereas the 2020 survey results exclude those costs. Where possible we apply a geographic weighting across regions to approximate the distribution of the survey respondents. NREL provides a range of cost projections in its Annual Technology Baseline (ATB). The IEA offers two projections in its World Energy Outlook (WEO).

elicitation $^{27}$ and recent literature ${ }^{7,32,50-52}$, these reductions are predicted to be the result of changes across all major LCOE cost and performance components. Forecasts that centre primarily on CapEx reductions probably capture at most around $45 \%$ of the overall cost-reduction potential. These trends and expectations might enable wind to play a larger role in global energy supply than previously thought while facilitating energy-sector decarbonization. As costs decline, additional focus may turn to the value of wind in energy markets ${ }^{53-56}$ and to deployment barriers such as human-use conflicts, wildlife impacts and transmission needs ${ }^{57-60}$.

Among cost-forecasting methods, expert elicitation offers a relatively straightforward approach to estimating uncertainty. The wind energy expert elicitations from 2015 and 2020 illustrate uncertainties across the low-, median- and high-cost scenarios, and among the range of expert responses. Actual onshore and offshore wind costs since 2014 have declined more rapidly than the vast majority of experts predicted in 2015 , even in the low-cost (10\% probability) scenario, further highlighting the depth and pervasiveness of uncertainties. These results should give pause to those who use point forecasts for future costs, and they suggest that energy-sector modellers should account for cost uncertainties. More broadly, the results demonstrate the importance of fully considering uncertainty in energy policymaking, planning, investment and research decisions.

It is perhaps premature after five years to assess an elicitation that sought cost estimates out to 2050. Nonetheless, given the dearth and importance of such validations ${ }^{22,29}$, our early effort holds possible implications for the execution of elicitations. First, our analysis of expert predictions by organization type, level and type of expertise, and other characteristics reinforces the general importance of expert selection, though we find fewer differences than we anticipated. Second, our results add to the evidence suggesting overconfidence might be a concern, leading experts to understate uncertainty in outcomes. Those designing elicitations should assess potential overconfidence and apply protocols to reduce its impact. Third, despite concerns that experts may be overly optimistic, the opposite has been true, at least over the past five years for wind. As with several past solar elicitations ${ }^{22}$, wind experts in 2015 underestimated the pace of cost reduction. Additional and longer-duration validation efforts are needed to investigate the persistence of the various biases, enabling more universally applicable findings.

\section{Methods}

Elicitation survey. We obtained data through an online expert elicitation survey (via the Qualtrics survey software platform) under the auspices of IEA Wind Task 26 on the Cost of Wind Energy. The design leveraged the 2015 effort, but also included a number of notable revisions as discussed further below. The survey was designed over the course of more than six months, including multiple rounds of review, testing and revision. Advisors and reviewers included the authors of this paper, IEA Wind Task 26 members and a number of external wind energy experts (see the Acknowledgements for a full list). The survey and its implementation were approved by the relevant Human and Animal Research Committee at Lawrence Berkeley National Laboratory, ensuring compliance with ethical guidelines when surveying human subjects. Supplementary Note 4 includes a printed version of the final survey. As indicated in the text of the survey and in our communications with potential respondents, participation was voluntary and respondents offered their informed consent. The survey was launched in July 2020 and closed in early September 2020, roughly five years after the original survey ${ }^{27}$. To start the survey execution, we "pre-announced" the survey to possible respondents. The online survey was subsequently distributed with personalized web links. We emailed potential respondents six times to encourage responses before the survey closed, including personalized and less-personalized reminders.

Survey respondents. Our approach to constructing the survey sample was broadly similar to our approach in 2015. Given the focus on LCOE, an ideal respondent was a system-level thought leader with broad but thorough wind technology, cost and/or market expertise. Many expert elicitations feature lengthy in-person interviews with fewer than 20 experts $^{22}$. In contrast, as in 2015, we sought a much larger number of respondents-partly to enable comparisons across the two elicitations but also because our effort involved three distinct wind applicationsand we wished to assess responses by geographic region and other respondent-level characteristics. The Supplementary Methods associated with the earlier paper 
highlight key trade-offs involved with an online elicitation, including the need for a shorter survey than would be common in an in-person setting, with less in-depth exploration of responses ${ }^{27}$.

The survey was global in scope. We started with the sample from 2015. Every possible respondent was judged again, with many individuals dropped for various reasons-retirement, moving out of the wind industry and so on. We then added a large number of new experts. We received important help in identifying possible respondents from IEA Wind members, and we reached out to other experts to solicit recommendations. We also implemented "snowball" sampling, encouraging those in our original sample to suggest other respondents. We sought to increase the diversity of the sample relative to 2015, with greater representation from Asia and emerging markets, though, as detailed further below, respondents remained heavily skewed towards North America and Europe. In addition to the full survey sample, we identified a smaller group of leading experts. These individuals were selected through an iterative process by the authors and with the assistance of other external wind experts. We believe this smaller group to be uniquely qualified. As previously, we created this group in part to enable a comparison of results between a smaller subsample that follows a more-traditional elicitation and the larger set of all respondents. Additionally, in the 2015 elicitation, we found that the leading experts tended to expect more sizable cost reductions than the larger sample-an expectation that has so far proven accurate. We wanted to see whether this leading-expert cohort, in 2020, also held distinct perspectives relative to the larger sample.

We distributed surveys to 645 experts, including 184 leading experts. We received a total of 140 responses, of which 55 came from the leading-expert group. This reflects a response rate of $22 \%$ across the full sample and $30 \%$ among the smaller group. The absolute number of responses compares favourably to the 2015 survey of 163 in total and 22 from the leading group. However, the response rate in 2015 was higher, at $34 \%$ for the full sample and $52 \%$ for the leading group. Executing the survey in the middle of the COVID-19 pandemic and the summer vacation period may have contributed to the lower overall response rate.

Supplementary Table 4 highlights the characteristics of the 140 respondents by: wind application area ( 97 onshore, 71 fixed-bottom offshore, 37 floating offshore); region of the world for onshore/fixed-bottom offshore/floating offshore (North America (46/18/5, respectively), Europe (39/44/29, respectively), Asia (6/5/1, respectively), Central and South America (1/0/0, respectively), global average (3/4/2, respectively)); organizational type (31 wind developers, owners, financiers, operators and/or construction contractors; 24 wind turbine and/or component manufacturers; 31 others in the private-sector wind industry; 36 in academia and/or a public research or research management institution; and 18 others including government and non-profits not included in the other categories); and type of expertise (72 wind energy markets and/or cost analysis; 58 systems-level wind technologies focused on the entire wind turbine and/or wind plant; and 9 subsystems-level wind technologies focused on specific wind-turbine and/or wind-plant subsystems or components). Supplementary Table 5 lists the 140 respondents by name and organization, while also identifying which of those experts had been pre-identified as leading experts. As for the confidentiality of the responses, participants were provided the following information: "Participation in the survey is voluntary. If you choose to participate, your name and affiliation will be listed in the final report as a survey respondent. However, your individual survey responses will be kept in confidence and will not be attributed to you or your organization."

Elicitation methods. Well-designed elicitations follow certain protocols to enhance the value of the resulting data. As with the previous survey, we applied these basic concepts, tools and guidelines to minimize biases. We do not provide a full recounting of our approaches here, because they are generally similar to those employed in 2015 (see the original study for more detail ${ }^{27}$ ). As with the previous effort, though, the online format presented both challenges (such as limited ability for follow-up) and possible advantages (such as calculation and graphical tools that offer immediate feedback) over interview-based elicitations. As with any elicitation, it is not possible to fully eliminate motivational or cognitive biases. Well-designed elicitations can therefore be viewed as a means of revealing the views of subject-matter experts, but not necessarily revealing the absolute "truth."

Scope of assessment. Consistent with the 2015 effort, the survey focused on potential changes in the LCOE of wind projects across three distinct applications: onshore wind, fixed-bottom offshore wind and floating offshore wind. The LCOE of a project is equivalent to the minimum US\$ $\mathrm{MWh}^{-1}$ price a project must earn to cover all project costs, service debt, pay expected returns to equity shareholders and pay income tax. In our case, LCOE is calculated at the plant boundary. It excludes any valuation of societal benefits and does not consider project-level government financial support. The formula used to calculate LCOE and more details on its use can be found in the survey itself (Supplementary Note 4).

We sought LCOE estimates for the three wind applications at four distinct commercial operation dates: a recent-cost baseline for 2019 and then for 2025, 2035 and 2050. Including a 2019 baseline allowed for any changes over time to be characterized in absolute (US\$) or relative (percentage increase or decrease) terms. As in 2015, we did not seek a baseline for floating offshore wind, given the limited number of commercial projects installed. For the 2019 baseline year, and for the focus year of 2035, we requested details on five core input components of LCOE: CapEx, OpEx, capacity factor, design life and WACC. For CapEx, we asked respondents to include only costs within the plant boundary. This means that the costs for electrical cabling within a plant are in scope, but that any needed substation, transmission line or grid interconnection costs are not. For offshore wind, it also means that CapEx is inclusive of within-plant array cabling, but that CapEx, and therefore LCOE estimates, do not include costs associated with offshore substations and the grid connection to land. The WACC represents the average return required by equity and debt investors. To calculate LCOE, we applied standardized taxation and inflation assumptions, specifically, a $25 \%$ income tax rate, 20 -year straight-line tax depreciation and a $2 \%$ per year inflation rate. Please note that the 20-year period here is only used in calculating tax liabilities. Respondents typically estimated project design life to exceed 20 years, which is also used to calculate LCOE (Supplementary Fig. 7). The respondents saw these LCOE calculations in real time. For 2025 and 2050, we sought LCOE estimates but did not ask respondents to build those up from the five core input parameters.

All monetary values were presented in real 2019 US\$ and Euros.

As in 2015, the survey emphasized the "typical" LCOE of projects in each respondent's primary region of expertise. We defined "typical" as the median project in terms of costs (see the survey in Supplementary Note 4). Future LCOEs are uncertain. They can be affected by project-specific factors such as wind-resource quality impacting capacity factors, site-access conditions impacting CapEx, and so on. However, LCOEs can also be affected by factors that apply to the entire wind sector, such as overall wind technology advancement or a general move towards lower-quality or deeper-water wind sites. For 2025, 2035 and 2050, we asked respondents to provide estimates for a low-LCOE scenario (only a $10 \%$ chance that typical LCOE will be lower), a high-LCOE scenario (only $10 \%$ chance that typical LCOE will be higher) and a median-LCOE scenario (equally likely that LCOE will be higher or lower), considering only the broader, non-project-specific factors. Specifically, we asked respondents to focus on changes in the typical LCOE (that is, to ignore project-to-project variation) that might result from changes in factors that affect the industry as a whole. We further asked respondents to assume no changes in macroeconomic conditions, materials and commodity prices, and other factors not directly related to the wind energy business. Importantly, we asked the respondents to disregard the potential near-term impacts of COVID-19 in their responses. We invited respondents to provide a narrative description of the factors that might lead to their 2035 low-, high- and median-scenario LCOE estimates.

For each of the three wind applications, we also asked respondents to provide the geographic region for which their estimates applied. Additionally, we asked about several core project and site conditions that the respondent was thinking about when providing their typical LCOE estimate for 2019, and their median-cost scenario LCOE estimate for 2035. For onshore wind, we focused on average annual wind speed at a 100-m hub height, enabling a better understanding of how respondents expect typical site conditions to change over time. For fixed-bottom and floating offshore wind, we asked for further details, covering not only average annual wind speeds for typical projects in 2019 and 2035, but also typical water depth, distance to shore and project size. Each of these site characteristics can influence LCOE. As such, when paired with estimates of typical LCOE, they enable a deeper understanding of LCOE drivers.

In addition to asking about LCOE, the five core LCOE inputs, and project and site conditions, we included several other questions in the survey. First, we sought information on expected turbine characteristics for onshore and offshore wind projects installed in 2035: nameplate capacity, hub height and rotor diameter. Second, we asked about the relative impact of various constraints that may limit further growth in turbine size, both onshore and offshore. Third, for onshore wind, we asked about the potential influence of different factors that might drive turbine choice for specific sites in 2035, whereas for offshore wind we explored possible trade-offs in the application of fixed-bottom and floating technology. Finally, for both onshore and offshore wind, we asked about the likely use in 2035 of various strategies to boost the value of wind to the electricity system. The responses to many of these supplemental questions are not addressed in the present paper, but are available separately $y^{61}$.

Respondents could choose to answer questions related to onshore and offshore wind, or select just one of the two. We asked all respondents answering questions about offshore wind to provide a 2019 baseline for fixed-bottom offshore, but they could then elect to provide future LCOE estimates for fixed-bottom, floating or both. We offered respondents the choice of using US\$ or Euros when taking the survey, and provided a currency calculator for those who were more familiar with other currencies. Additional details on all of these matters can be found in the survey (Supplementary Note 4 ).

Data interpretation and preparation. A limitation to an online survey format is that respondents may not fully comprehend precisely what is being asked of them, in part because they may choose to gloss over the textual instructions and explanations that precede the questions. There is little opportunity for the designer of the survey to interact with the respondents to clear up any such confusion. The result is that some questions may be left blank, and others answered but not as originally intended. This is true even with the most rigorously designed online elicitation. 
We were especially concerned about expert comprehension of a few of the key points noted earlier with respect to the LCOE questions. For example, we feared that respondents might think about project-level variations in costs, and establish the low- and high-cost scenarios in light of that project-level cost variation rather than differences in sector-wide advancements. We also feared that, despite our desires, respondents might consider macroeconomic factors in their estimates. Accordingly, in the survey we included relevant text and figures in multiple places to help the respondents understand the concepts of concern. We also feared that respondents might estimate low (10\% chance of being lower) and high ( $10 \%$ chance of being higher) future CapEx, OpEx, capacity factor, design life and WACC, whereas we wanted the respondents to estimate low, high and median scenarios of future LCOE. Naturally, the LCOE that results from the 10th percentile of each of the five factors would have a probability of occurrence well lower than $10 \%$. Here, too, we included relevant text in the survey.

In addition to designing the survey to reduce these concerns, the survey contained optional open-ended questions asking respondents to elaborate on the characteristics of their low-, high- and median-LCOE scenarios. Many experts opted to leave these text fields blank. However, of the 140 respondents, 73 answered at least one of these open-ended descriptive questions. We were pleasantly surprised. After reviewing the responses, it is clear that many experts understood what we were looking for. There were exceptions, where the response suggested some consideration of project-level variation, for example. But these were limited in number.

Unfortunately, during an early review of survey responses, we observed that a number of respondents' initial surveys were missing 2025 and 2050 LCOE estimates, probably due to browser compatibility issues with the original design of those questions. We reached out to these respondents to, in effect, reopen their surveys in case they wanted to offer estimates of those otherwise missing values. Also related to the 2025 and 2050 estimates, and perhaps again due to browser incompatibility, we observed a few cases where, for example, the low-case LCOEs were higher than the mid-case LCOEs. We also reached out to many of these experts, in case they wanted to revise their estimates. Even after these attempts, some missing values and inconsistencies remained. During data cleaning, we therefore removed estimates that featured these remaining inconsistencies.

We conducted no other data cleaning; the data presented in this paper are otherwise as delivered to us through the survey instrument. Because of this limited data cleaning, the number of respondents to any individual question varies. Additionally, some questions were no doubt misinterpreted. Consequently, we place most emphasis on the median of the survey responses and, secondarily, on the interior 25th to 75 th percentile ranges of responses. This is not to say that a full $50 \%$ of the respondents (those outside the interquartile range) misinterpreted the survey, and we present the full set of LCOE and 5-factor results in Supplementary Figs. 3-8. But we believe that focusing on the median result from all respondents (rather than the mean, which is impacted more by outliers and the tails of the distribution) and the interquartile range of all responses are reasonable means of depicting the central tendencies and range of results from the elicitation, while at least partially addressing the possibility of question misinterpretation.

Changes from 2015 to 2020 survey. The 2020 survey had many commonalities with the 2015 survey: consistent overall goals, numerous matching questions and similar functionality. This is to be expected because core goals of the 2020 effort were to update the earlier assessment and to compare the two sets of elicitation results. That said, a number of adjustments were made to the 2020 version of the survey, in part leveraging lessons learned from 2015 effort. Here we list the most notable revisions and briefly describe the underlying motivation for the changes. First, we paid particular attention to our survey sample, especially to try to enhance geographic diversity and carefully curate the leading-expert group. The result was greater geographic representation among the respondents than presumably otherwise would have been the case (though the respondents are still dominated by experts from North America and Europe) and heightened confidence in the selection and diversity of the leading-expert cohort. The former is especially important because wind power deployment has rapidly expanded outside of North America and Europe, especially in Asia; generally, past energy technology elicitations have focused on the United States and Europe, with wider regional coverage representing an important gap in the literature ${ }^{16}$. Second, with five intervening years, we updated the dates of our assessment-to 2019, 2025, 2035 and 2050 instead of 2014,2020, 2030 and 2050. We remained interested in assessing the starting point baseline (2014 for the 2015 survey, and 2019 for the 2020 survey); we also remained interested in long-term predictions, so we included the year 2050 in both surveys. The 2015 survey asked for estimates in 2020. In 2020 , we would have gleaned little additional information asking for 2020 estimates when we were already asking for a 2019 baseline, so we shifted that assessment by five years, to 2025 . With 2025 and 2050 estimates chosen, we felt that 2035 offered a useful intermediate point for the 2020 survey; selecting 2030 as we did under the 2015 survey would have placed relatively heavier weight on the near term than we preferred. Third, we required each respondent to provide a 2019 baseline LCOE estimate from which their future expectations are compared. In contrast, the 2015 survey offered respondents a predefined 'default' 2014 baseline value and gave them the option (but not the obligation) to update that value. This may have created anchoring bias. The majority of respondents in 2015 simply selected the default baseline value. While those respondents may truly have subscribed to the default value, many probably were seeking to reduce their time commitment on the survey. Our approach in 2020 closed that loophole, ensuring that respondents were more committed to their baseline, from which their future estimates are judged. By then comparing future cost estimates with respondent-specific baselines in percentage terms, we normalize for the very different baseline costs expected for different parts of the globe. Fourth, we asked each respondent for information on project and site conditions for their 2019 baseline and 2035 median-cost LCOE estimates. The responses to these questions enable a deeper understanding of LCOE expectations, specifically the degree to which they are likely to be impacted by systematic technology change or changes in project sites and characteristics. We had no analogous questions in the 2015 survey. When paired with estimates of typical LCOE, they enable a deeper understanding of LCOE drivers. Fifth, recognizing that many of our respondents probably do not have deep expertise in project finance, the 2020 survey included more information on WACC, offered a calculator that respondents could use to estimate WACC and provided additional guidance on this input parameter. Finally, we asked several questions that are related but not critical to the primary purposes of the survey; we did the same in 2015 , but with a different set of supplemental questions.

Reporting Summary. Further information on research design is available in the Nature Research Reporting Summary linked to this article.

\section{Data availability}

Respondent-level data from the 2020 survey are provided in Supplementary Data 1, albeit with personal identifiers eliminated. Answers to the small number of questions that were open-ended, inviting narrative responses, are not included to help ensure the confidentiality of the respondents to the survey. Data underlying the figures in the Supplementary Information are provided as Supplementary Data 2. Source data are provided with this paper.

\section{Code availability}

Most data cleaning, analysis and figure creation was performed using R statistical software, including code from the tidyverse, scales and ggpmisc packages. The regressions were also implemented in R statistical software. All scripts are available upon request from the corresponding author.

Received: 10 November 2020; Accepted: 5 March 2021; Published online: 15 April 2021

\section{References}

1. Lazard's Levelized Cost of Energy Analysis-Version 14.0 (Lazard, 2020).

2. Barthelmie, R. J. \& Pryor, S. C. Potential contribution of wind energy to climate change mitigation. Nat. Clim. Change 4, 684-688 (2014).

3. Luderer, G. et al. Assessment of wind and solar power in global low-carbon energy scenarios: an introduction. Energy Econ. 64, 542-551 (2017).

4. Pietzcker, R. C. et al. System integration of wind and solar power in integrated assessment models: a cross-model evaluation of new approaches. Energy Econ. 64, 583-599 (2017).

5. Bistline, J. E. et al. Electric sector policy, technological change, and U.S. emissions reductions goals: results from the EMF 32 model intercomparison project. Energy Econ. 73, 307-325 (2018).

6. Renewable Power Generation Costs in 2019 (IRENA, 2020)

7. Duffy, A. et al. Land-based wind energy cost trends in Germany, Denmark, Ireland, Norway, Sweden and the United States. Appl. Energy 277, 114777 (2020).

8. Jansen, M. et al. Offshore wind competitiveness in mature markets without subsidy. Nat. Energy 5, 614-622 (2020).

9. Veers, P. et al. Grand challenges in the science of wind energy. Science 366, eaau2027 (2019).

10. Watson, S. et al. Future emerging technologies in the wind power sector: a European perspective. Renew. Sustain. Energy Rev. 113, 109270 (2019).

11. Zhang, X., Ma, C., Song, X., Zhou, Y. \& Chen, W. The impacts of wind technology advancement on future global energy. Appl. Energy 184, 1033-1037 (2016).

12. Mai, T. T., Lantz, E. J., Mowers, M. \& Wiser, R. The Value of Wind Technology Innovation: Implications for the U.S. Power System, Wind Industry, Electricity Consumers, and Environment (National Renewable Energy Laboratory, 2017).

13. Bistline, J. E. T. \& Young, D. T. Economic drivers of wind and solar penetration in the US. Environ. Res. Lett. 14, 124001 (2019).

14. Cranmer, A. \& Baker, E. The global climate value of offshore wind energy. Environ. Res. Lett. 15, 054003 (2020).

15. Morgan, M. G. Use (and abuse) of expert elicitation in support of decision making for public policy. Proc. Natl Acad. Sci. USA 111, 7176-7184 (2014).

16. Anadón, L. D., Baker, E. \& Bosetti, V. Integrating uncertainty into public energy research and development decisions. Nat. Energy 2, 1-14 (2017). 
17. Morgan, M. G. \& Henrion, M. Uncertainty: A Guide to Dealing with Uncertainty in Quantitative Risk and Policy Analysis (Cambridge Univ. Press, 1990).

18. Cooke, R. Experts in Uncertainty: Opinion and Subjective Probability in Science (Oxford Univ. Press, 1991).

19. O'Hagan, A. et al. Uncertain Judgements: Eliciting Experts' Probabilities (Wiley, 2006).

20. Meyer, M. A. \& Booker, J. M. Eliciting and Analyzing Expert Judgment: A Practical Guide (Society for Industrial and Applied Mathematics and American Statistical Association, 2001).

21. Hora, S. C. in Advances in Decision Analysis: From Foundations to Applications (eds Edwards, W. et al.) 129-153 (Cambridge Univ. Press, 2007).

22. Verdolini, E., Anadón, L. D., Baker, E., Bosetti, V. \& Aleluia Reis, L. Future prospects for energy technologies: insights from expert elicitations. Rev. Environ. Econ. Policy 12, 133-153 (2018)

23. Junginger, M. \& Louwen, A. Technological Learning in the Transition to a Low-Carbon Energy System (Academic, 2020).

24. Samadi, S. The experience curve theory and its application in the field of electricity generation technologies-a literature review. Renew. Sustain. Energy Rev. 82, 2346-2364 (2018)

25. Malhotra, A. \& Schmidt, T. S. Accelerating low-carbon innovation. Joule 4, 2259-2267 (2020).

26. Bolinger, $M$. et al. Opportunities for and challenges to further reductions in the "specific power" rating of wind turbines installed in the United States. Wind Eng. https://doi.org/10.1177/0309524X19901012 (2020).

27. Wiser, R. et al. Expert elicitation survey on future wind energy costs. Nat. Energy 1, 16135 (2016).

28. Bonaccorsi, A., Apreda, R. \& Fantoni, G. Expert biases in technology foresight. Why they are a problem and how to mitigate them. Technol. Forecast. Soc. Change 151, 119855 (2020).

29. Colson, A. R. \& Cooke, R. M. Expert elicitation: using the classical model to validate experts' judgments. Rev. Environ. Econ. Policy 12, 113-132 (2018).

30. Edenhofer, O. et al. On the economics of renewable energy sources. Energy Econ. 40, S12-S23 (2013).

31. Wiser, R. et al. Wind Energy Technology Data Update: 2020 Edition (Lawrence Berkeley National Laboratory, 2020).

32. Egli, F., Steffen, B. \& Schmidt, T. S. A dynamic analysis of financing conditions for renewable energy technologies. Nat. Energy 3, 1084-1092 (2018).

33. Steffen, B. Estimating the cost of capital for renewable energy projects. Energy Econ. 88, 104783 (2020).

34. Rohrig, K. et al. Powering the 21 st century by wind energy-options, facts, figures. Appl. Phys. Rev. 6, 031303 (2019)

35. Vieira, M., Snyder, B., Henriques, E. \& Reis, L. European offshore wind capital cost trends up to 2020. Energy Policy 129, 1364-1371 (2019).

36. Wind Energy in Europe in 2019: Trends and Statistics (WindEurope, 2020).

37. Musial, W. et al. 2019 Offshore Wind Technology Data Update (NREL, 2020).

38. Voormolen, J. A., Junginger, H. M. \& van Sark, W. G. J. H. M. Unravelling historical cost developments of offshore wind energy in Europe. Energy Policy 88, 435-444 (2016).

39. Renewable Power Generation Costs in 2017 (IRENA, 2018).

40. Williams, E., Hittinger, E., Carvalho, R. \& Williams, R. Wind power costs expected to decrease due to technological progress. Energy Policy 106 427-435 (2017).

41. World Energy Outlook (IEA, 2020).

42. International Energy Outlook 2019 (EIA, 2019).

43. New Energy Outlook 2020 (BloombergNEF, 2020).

44. Energy Transition Outlook 2020 (DNV GL, 2020).

45. Global Renewables Outlook: Energy Transformation 2050 (IRENA, 2020).

46. Annual Energy Outlook 2020 (EIA, 2020).

47. 1H 2020 LCOE Update (BloombergNEF, 2020).

48. 2020 Annual Technology Baseline (NREL, 2020).

49. Yang, S., Lassen, S. \& Kragelund, R. Global Bottom-Fixed Offshore Wind LCOE (Wood Mackenzie, 2019).

50. Wiser, R. \& Bolinger, M. Benchmarking Anticipated Wind Project Lifetimes: Results from a Survey of U.S. Wind Industry Professionals (Lawrence Berkeley National Laboratory, 2019).

51. Steffen, B., Beuse, M., Tautorat, P. \& Schmidt, T. S. Experience curves for operations and maintenance costs of renewable energy technologies. Joule 4 359-375 (2020).

52. Wiser, R., Bolinger, M. \& Lantz, E. Assessing wind power operating costs in the United States: results from a survey of wind industry experts. Renew. Energy Focus 30, 46-57 (2019).

53. Hirth, L. \& Müller, S. System-friendly wind power: how advanced wind turbine design can increase the economic value of electricity generated through wind power. Energy Econ. 56, 51-63 (2016).

54. Wiser, R., Millstein, D., Bolinger, M., Jeong, S. \& Mills, A. The hidden value of large-rotor, tall-tower wind turbines in the United States. Wind Eng. https://doi.org/10.1177/0309524X20933949 (2020).

55. Gorman, W. et al. Motivations and options for deploying hybrid generatorplus-battery projects within the bulk power system. Electr. J. 33, 106739 (2020).
56. Das, S., Hittinger, E. \& Williams, E. Learning is not enough: diminishing marginal revenues and increasing abatement costs of wind and solar. Renew. Energy 156, 634-644 (2020).

57. McKenna, R., Ostman v.d. Leye, P. \& Fichtner, W. Key challenges and prospects for large wind turbines. Renew. Sustain. Energ. Rev. 53, 1212-1221 (2016)

58. Gorman, W., Mills, A. \& Wiser, R. Improving estimates of transmission capital costs for utility-scale wind and solar projects to inform renewable energy policy. Energy Policy 135, 110994 (2019).

59. Rand, J. \& Hoen, B. Thirty years of North American wind energy acceptance research: what have we learned? Energy Res. Soc. Sci. 29, 135-148 (2017).

60. Schuster, E., Bulling, L. \& Köppel, J. Consolidating the state of knowledge: a synoptical review of wind energy's wildlife effects. Environ. Manage. 56, 300-331 (2015).

61. Wiser, R. et al. Expert Predictions about the Future Cost of Onshore and Offshore Wind Energy (Lawrence Berkeley National Laboratory, 2021).

\section{Acknowledgements}

This study was conducted under the auspices of the IEA Wind Implementing Agreement for Cooperation in the Research, Development, and Deployment of Wind Energy Systems (IEA Wind). It is authored by staff at Lawrence Berkeley National Laboratory, funded by the US Department of Energy (DOE) under contract no. DE-AC02$05 \mathrm{CH} 11231$ (R.W., J.R., J.S.). It is also authored by staff at the NREL, operated by Alliance for Sustainable Energy, LLC, for the DOE under contract no. DE-AC36-08GO28308 (P.B., E.L.). Funding was provided by the DOE Office of Energy Efficiency and Renewable Energy, Wind Energy Technologies Office. The views expressed here do not necessarily represent the views of the DOE or the US Government. The US Government retains and the publisher, by accepting the article for publication, acknowledges that the US Government retains a nonexclusive, paid-up, irrevocable, worldwide license to publish or reproduce the published form of this work, or allow others to do so, for US Government purposes. We especially thank our IEA Wind collaborators: V. Berkhout, G. Bohan, J. Hethey, S. Kalash, L. Kitzing, Y. Kikuchi, S. Lüers, M. Noonan, A. M. Østenby, A. Dalla Riva, T. Stehly, M. Stenkvist and T. Telsnig. These collaborators were involved from the outset of this project: offering crucial feedback on overall objectives, survey design and specific questions; piloting draft versions of the survey; and suggesting experts to include in the sample. For additional assistance in identifying possible survey respondents and/or the curation of the leading expert group, we thank: I. Martí, K. Ohlenforst, H. Stiesdal, M. Hall, F. Zhao, D. Weir, P.-J. Rigole, F. Klein, S. Barth C. Bottasso, G. Smart, P. Veers, K. Ralston, A. Gambhir, J. Hensley, W. Musial, G. Du, A. Smith, I. Komusanac, A. Lemke, J. Lee and A. Pek. For input on survey objectives and design, we also thank R. Tusing, M. Taylor, M. Bolinger, J. McCann, K. Ohlenforst, K. Dykes and A. Barr. The survey was implemented online via Qualtrics software, but required considerable customization. We greatly appreciate WALKER for assistance in survey implementation and execution, with special thanks to R. Fanning, J. Connolly and J. Wiggington. Of course, this work would not have been possible without the gracious contributions of the experts who chose to participate in the survey. We list those individuals and their affiliated organizations in Supplementary Table 5.

\section{Author contributions}

All authors contributed to formulating the research, constructing the survey, and discussing, reviewing and revising the paper. R.W. led the overall effort and drafted most of the paper. R.W., P.B. and E.L. each contributed substantially to the creation of the survey sample. J.S. and J.R. led the implementation and execution of the online survey. J.R. led the analysis of the survey responses, with assistance from R.W. E.B. provided insight on expert elicitation design. P.G. provided overall guidance, including on survey goals and objectives.

\section{Competing interests}

The authors declare the following competing interest: P.G. is employed by the US Department of Energy, which provided research support funding for the work described in this article. P.G. contributed to formulating the research, constructing the survey, and discussing, reviewing and revising the paper. The authors contend that this competing interest had no bearing on the results or findings of the work, as presented in the current paper.

\section{Additional information}

Supplementary information The online version contains supplementary material available at https://doi.org/10.1038/s41560-021-00810-z.

Correspondence and requests for materials should be addressed to R.W.

Peer review information Nature Energy thanks Roger Cooke, John Paul Gosling and Malte Jansen for their contribution to the peer review of this work

Reprints and permissions information is available at www.nature.com/reprints. Publisher's note Springer Nature remains neutral with regard to jurisdictional claims in published maps and institutional affiliations.

(c) The Author(s), under exclusive licence to Springer Nature Limited 2021 


\section{Reporting Summary}

Nature Research wishes to improve the reproducibility of the work that we publish. This form provides structure for consistency and transparency in reporting. For further information on Nature Research policies, see our Editorial Policies and the Editorial Policy Checklist.

\section{Statistics}

For all statistical analyses, confirm that the following items are present in the figure legend, table legend, main text, or Methods section.

n/a Confirmed

$\bigotimes$ The exact sample size $(n)$ for each experimental group/condition, given as a discrete number and unit of measurement

Х A statement on whether measurements were taken from distinct samples or whether the same sample was measured repeatedly

X The statistical test(s) used AND whether they are one- or two-sided

$\triangle$ Only common tests should be described solely by name; describe more complex techniques in the Methods section.

Х $\square$ A description of all covariates tested

Х $\square$ A description of any assumptions or corrections, such as tests of normality and adjustment for multiple comparisons

$\triangle$ A full description of the statistical parameters including central tendency (e.g. means) or other basic estimates (e.g. regression coefficient)

$\triangle 1$ AND variation (e.g. standard deviation) or associated estimates of uncertainty (e.g. confidence intervals)

$\searrow \square \begin{aligned} & \text { For null hypothesis testing, the test statistic (e.g. } F, t, r \text { ) with confidence intervals, effect sizes, degrees of freedom and } P \text { value noted } \\ & \text { Give } P \text { values as exact values whenever suitable. }\end{aligned}$

Х $\square$ For Bayesian analysis, information on the choice of priors and Markov chain Monte Carlo settings

Х $\square$ For hierarchical and complex designs, identification of the appropriate level for tests and full reporting of outcomes

$\bigotimes \square$ Estimates of effect sizes (e.g. Cohen's d, Pearson's $r$ ), indicating how they were calculated

Our web collection on statistics for biologists contains articles on many of the points above.

\section{Software and code}

Policy information about availability of computer code

Data collection We obtained data through an online survey developed and executed using Qualtrics XM software.

Data analysis Data cleaning, analysis, and figure-creation was performed using R statistical software, version 4.0.2, including packages from the tidyverse, scales, and ggpmisc packages. The regressions discussed in the SI were also implemented in R version 4.0.2.

For manuscripts utilizing custom algorithms or software that are central to the research but not yet described in published literature, software must be made available to editors and

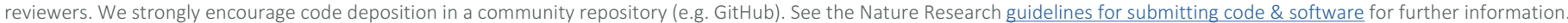

Data

Policy information about availability of data

All manuscripts must include a data availability statement. This statement should provide the following information, where applicable:

- Accession codes, unique identifiers, or web links for publicly available datasets

- A list of figures that have associated raw data

- A description of any restrictions on data availability

Respondent-level data from the 2020 survey are provided in a supplementary data file, albeit with personal identifiers eliminated. Answers to the small number of questions that were open-ended, inviting narrative responses, are not included to help ensure the confidentiality of the respondents to the survey. Data underlying the figures are also provided as supplemental data files. 
Please select the one below that is the best fit for your research. If you are not sure, read the appropriate sections before making your selection.

Life sciences $\quad$ Behavioural \& social sciences Ecological, evolutionary \& environmental sciences

For a reference copy of the document with all sections, see nature.com/documents/nr-reporting-summary-flat.pdf

\section{Behavioural \& social sciences study design}

All studies must disclose on these points even when the disclosure is negative.

Study description

Research sample

Sampling strategy

Data collection

Timing

Data exclusions

Non-participation

Randomization
The study is based on an expert elicitation survey of 140 global wind energy experts, resulting in quantitative data on the levelized cost of wind energy (LCOE) for a 2019 baseline and three points in the future $(2025,2035$, and 2050) under three cost scenarios (low, median, and high). We followed established expert elicitation protocols to minimize biases and enhance the value of the resulting data.

The research sample consisted of international experts in the LCOE of wind energy. Given the focus on LCOE, an ideal respondent was a system-level thought leader with broad but thorough wind technology, cost, and/or market expertise. Many expert elicitations feature lengthy in-person interviews with fewer than 20 experts. In contrast, we sought a much larger number of respondentspartly because our effort involved three distinct wind applications, and we wished to assess responses by geographic region and other respondent-level characteristics.

The survey was global in scope. We started with the sample from a similar elicitation we led in 2015. Every possible respondent was judged again, with many individuals dropped for various reasons - retirement, moving out of the wind industry, etc. We then added a large number of new experts. We received important help in identifying possible respondents from IEA Wind members, and we reached out to other experts to solicit recommendations. We also implemented "snowball" sampling, encouraging those in our original sample to suggest other respondents. We sought to increase the diversity of the sample relative to 2015, with greater representation from Asia and emerging markets - though, as detailed in the article's Methods section, respondents remained heavily skewed towards North America and Europe. In addition to the full survey sample, we identified a smaller group of 'leading experts.' These individuals were selected through an iterative process by the authors and with the assistance of other external wind experts. We believe this smaller group to be uniquely qualified.

We obtained data through an online expert elicitation survey (via the Qualtrics XM survey software platform) under the auspices of IEA Wind Task 26 on the "Cost of Wind Energy." To start the survey execution, we "pre-announced" the survey to possible respondents. The online survey was subsequently distributed with personalized web links. We emailed potential respondents six times to encourage responses before the survey closed, including personalized and less-personalized reminders.

The survey was launched on July 20, 2020. The survey closed and data collection ceased on September 11, 2020

We observed that 31 respondents' initial surveys were missing 2025 and 2050 LCOE estimates, likely due to browser compatibility issues with the original design of those questions. We reached out to these respondents to, in effect, reopen their surveys in case they wanted to offer estimates of those otherwise-missing values. 27 respondents' missing data were rectified through this process. Also related to the 2025 and 2050 estimates, and perhaps again due to browser incompatibility, we observed a few cases where-for example-the low-case LCOEs were higher than the mid-case LCOEs. These were deemed to be errors. During data cleaning, we removed estimates that featured these inconsistencies. In total, this data cleaning affected one or more data points for 18 respondents. We conducted no other data cleaning: the data presented in this paper are otherwise as delivered to us through the survey instrument.

We distributed surveys to 645 experts, including 184 'leading experts.' We received a total of 140 responses, of which 55 came from the leading-expert group. This reflects a response rate of $22 \%$ across the full sample and $30 \%$ among the smaller group.

In addition to the full survey sample, we identified a smaller group of 'leading experts.' These individuals were selected through an iterative process by the authors and with the assistance of other external wind experts. We believe this smaller group to be uniquely qualified. This grouping was non-random.

\section{Reporting for specific materials, systems and methods}

We require information from authors about some types of materials, experimental systems and methods used in many studies. Here, indicate whether each material, system or method listed is relevant to your study. If you are not sure if a list item applies to your research, read the appropriate section before selecting a response. 


\begin{tabular}{l|l}
\hline n/a & Involved in the study \\
$\searrow$ & $\square$ Antibodies \\
$\searrow$ & $\square$ Eukaryotic cell lines \\
$\searrow$ & $\square$ Palaeontology and archaeology \\
$\square$ & $\square$ Animals and other organisms \\
$\square$ & $\square$ Human research participants \\
$\searrow$ & $\square$ Clinical data
\end{tabular}

\section{Human research participants}

Policy information about studies involving human research participants

Population characteristics

Recruitment

Ethics oversight
See above. Detailed descriptions and counts (by various groupings) are provided in Supplementary Table 1.

See above. We emailed potential respondents six times to encourage responses before the survey closed, including personalized and less-personalized reminders. Because the email communications and the survey instrument were only available in the English language, there may be a selection bias among our respondents toward those who can read and write in English. Although the survey sample was global in scope, respondents were heavily skewed toward those with expertise in Europe and North America. Data collection also occurred during the COVID-19 pandemic, the global impacts of which may have affected our response rate.

The study protocol was approved by the Human \& Animal Research Committee (HARC) at Lawrence Berkeley National Laboratory, ensuring compliance with ethical guidelines when surveying human subjects. Informed consent was granted by participants who advanced beyond the first page of the online survey. That first page provided basic instructions to participants, as well as information on how to withdraw from the survey during and after completion, protection of raw survey data, and contact information for concerns as a human subject. The following guidance on participation (and waiving anonymity) was provided: "Participation in the survey is voluntary. If you choose to participate, your name and affiliation will be listed in the final report as a survey respondent. However, your individual survey responses will be kept in confidence and will not be attributed to you or your organization." See Supplementary Note 4 (accompanying the main article text) for the full consent form, instructions, and complete survey instrument. 